\title{
RELATIONS AMONG SOME IMPORTANT ASTRONOMICAL CONSTANTS
}

\author{
By Dirk BROUWER, \\ Yale University Observatory.
}

RÉsumé. - La connaissance de valeurs précises, tant des coefficients $J_{2}, J_{4}, \ldots$ du potentiel terrestre que des distances radar TerreLune et Terre-Vénus, nous autorise désormais à utiliser des relations entre les constantes astronomiques, autres que celles qu'on a jusqu'à présent employées dans diverses tentatives de construire un système cohérent de constantes astronomiques. Certaines de ces relations, parmi les plus importantes, sont devenues plus simples.

Abstract. - The availability of accurate values of the coefficients $J_{2}, J_{4}, \ldots$ in the Earth's potential and radar determinations of the distances Earth-Moon and Earth-Venus provides relations among astronomical constants different in form from those used in previous efforts to construct a consistent system of astronomical constants. Some of the important relations have gained in simplicity.

Zusammenfassung. - Die vorhandenen genauen Werte der Koeffizienten $\mathbf{J}_{2}, \mathbf{J}_{4}, \ldots$ im Erdpotential und die Radar-Bestimmungen der Entfernungen Erde-Mond und Erde-Venus liefern Beziehungen zwischen den astronomischen Konstanten, die in der Form von denjenigen verschieden sind, welche in früheren Bemühungen zur Aufstellung eines widerspruchsfreien Systems astronomischer Konstanten benutzt wurden. Einige von den wichtigen Beziehungen sind dabei einfacher geworden.

Резюме. - Ныне известные точные значения коэффициентов $\mathrm{J}_{2}, \mathrm{~J}_{4}$, потенциала Земли и определенных радаром расстояний между Землей и Луной и между Землей и Венерой, позволяют нас в дальнейшем применять соотношения между астрономическими постоянными отличающихся от тех, которые до сих пор были в употреблении при попытках создать связную систему астрономических постоянных. Некоторые соотношения среди наиболее важных оказались более простыми. 
1. The basic formulas. - Three basic formulas are available to obtain relationships among the masses $\mathrm{S}$ of the Sun, $\mathrm{E}$ of the Earth, $\mathrm{M}$ of the Moon, the scales of the orbits, and the Earth's equatorial radius :

$$
\begin{gathered}
g_{0} b^{2}=\mathrm{F}_{1} \mathrm{GE}, \\
n_{\widetilde{\mathbb{C}}}^{2} a_{\mathbb{\mathbb { C }}}^{3}=\mathrm{F}_{2} \mathrm{G}(\mathrm{E}+\mathrm{I}), \\
k^{\prime 2} \mathbf{A}^{3}=\mathrm{GS},
\end{gathered}
$$

in which

$g_{0}$, the acceleration of gravity at the equator;

$b$, the Earth's equatorial radius;

$a_{\mathbb{c}}$, the mean distance between the centers of the Earth and the Moon;

A, the astronomical unit expressed in meters;

$\mathrm{G}$, the constant of gravitation;

$n_{\mathbb{C}}$, the Moon's mean motion

$=47434^{\prime \prime} .89$ ro per day

$=2.66 \mathrm{I} 6995 \times 1 \mathrm{I}^{-6} \mathrm{rad} / \mathrm{s}$;

$k=0.01720209895 \mathrm{rad} /$ day;

$k^{\prime}=\mathrm{I} .990983675 \times 10^{-7} \mathrm{rad} / \mathrm{s}$

$$
=\frac{k}{86400} \text {. }
$$

The factors $F_{1}, F_{2}$ are numerical factors, close to unity, that must be provided by celestial mechanics. The units to be used will be the meter as the unit of distance, the second as the unit of time. Thus the dimension of GE, GM, GS will be meters ${ }^{3} \cdot \mathrm{sec}^{-2}$.

2. The factor $F_{1}$. - It will be assumed that the Earth's surface can be represented by a spheroid; i. e. surface with rotational symmetry about the axis of rotation, and also with symmetry about the equatorial plane. Let $E_{1}$ be the mass of the Earth exclusive of the atmosphere. The surface of the geoid will be represented by the equipotential surface

$$
\begin{aligned}
\Psi=\frac{\mathrm{GE}_{1}}{\mathrm{R}}\left[\mathrm{I}-\mathrm{J}_{2} \frac{b^{2}}{\mathrm{R}^{2}} \mathrm{P}_{2}\left(\sin \varphi^{\prime}\right)\right. & -\mathrm{J}_{4} \frac{b^{4}}{\mathrm{R}^{4}} \mathrm{P}_{4}\left(\sin \varphi^{\prime}\right)-\ldots \\
& \left.+\frac{\mathrm{I}}{2} \frac{\omega^{2} \mathrm{R}^{3}}{\mathrm{GE}_{1}}\left(\mathrm{I}-\sin ^{2} \varphi^{\prime}\right)\right]=\text { const. }
\end{aligned}
$$

in which

$\varphi^{\prime}$, the geocentric latitude;

$\mathrm{J}_{2}, \mathrm{~J}_{4}, \ldots$ are coefficients to be obtained from observations;

$\mathrm{P}_{2}, \mathrm{P}_{4}, \ldots$, Legendre polynomials;

(w) the angular velocity of rotation of the Earth

$=\mathrm{I} 299548 . " 204$ per day

$=7.292115156 \times 10^{-\cdots ;} \mathrm{rad} / \mathrm{s}$;

$\omega^{2}=5.317494345 \times 10^{-9}$. 
Introduce

$$
i=\frac{(1)^{2} b: 3}{\mathrm{GE}_{1}}=\frac{(1)^{2} b}{g_{0}} \mathrm{~F}_{1} \frac{\mathrm{E}}{\mathrm{E}_{1}},
$$

$\frac{E}{E_{1}}$ is the ratio between the mass of the Earth with atmosphere to the mass of the Earth without atmosphere. The ratio is, sufficiently accurate for the present purpose,

$$
\frac{\mathrm{E}}{\mathrm{E}_{1}}=1.00000086
$$

Anticipating the result to be derived below, the value

$$
F_{1} \frac{E}{E_{1}}=0.99^{816586}
$$

will be used. Also following Fischer [1] :

$$
\begin{aligned}
& b=6378166 \mathrm{~m}, \\
& s_{0}=9.78030 \mathrm{~m} / \mathrm{s}^{2}, \\
& s=0.003 .961 \mathrm{1} .
\end{aligned}
$$

The expression 'I' = const., with

$$
\begin{aligned}
& R=b\left[1-\varepsilon_{2} \sin ^{2} c^{\prime}-\varepsilon_{4} \sin ^{i} y^{\prime}-\ldots\right], \\
& \xi=-\sec \left(\tau-\vartheta^{\prime}\right) \frac{\partial \Psi^{\prime}}{\partial R},
\end{aligned}
$$

yields

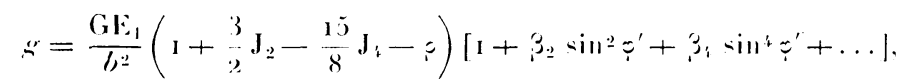

so that

$$
\begin{aligned}
F_{1} & =\left(1+\frac{3}{2} J_{2}-\frac{15}{8} J_{1}-5\right) \frac{E_{1}}{E} \\
& =\frac{0.998165-6}{1.00000086} \\
& =0.99^{8} 16.190
\end{aligned}
$$

in which use is made of Kozai's [2] latest results

$$
\begin{aligned}
& \mathrm{J}_{2}=+0.00108248 \\
& \mathrm{~J}_{4}=-0.0000018 .
\end{aligned}
$$

Inclusion of $\mathrm{J}_{\mathrm{i}}, \mathrm{J}_{\mathrm{s}}$ for which Kozai found $+39 \times \mathrm{IO}^{-8},-2 \times \mathrm{I}^{-8}$, changes $F_{1}$ to 0.99816580 .

A recent determination by D. G. King-Hele, C. F. Cook and Janice H. Rees [3] includes even values of the coefficients $J$ up to $J_{12}$ :

$$
\begin{aligned}
& 10^{\mathrm{s}} \mathrm{J}_{2}=+1082,8, \quad 10^{\mathrm{*}} \mathrm{J}_{\mathrm{s}}=+2 ., \\
& 10^{\mathrm{s}} \mathrm{J}_{4}=-\quad 78 ; \quad 10^{8} \mathrm{~J}_{10}=-50, \\
& 10^{*} \cdot J_{6}=+\quad 70, \quad 10^{*} J_{12}=+28 .
\end{aligned}
$$


D. BROUWER.

They find that the coefficient $J_{4}$ is affected sharply by the inclusion of $\mathrm{J}_{10}$. With these values,

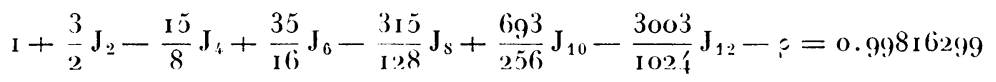

and

$$
\mathrm{F}_{1}=0.99^{8} \mathrm{16} 2 \mathrm{1} 3
$$

It appears that the sixth decimal place of $F_{1}$ may still be uncertain by several units, and that a more definitive determination of this coefficient may have to be obtained from geodetic satellites. In the following I have used

$$
F_{1}=0.99816500
$$

which yields $\mathrm{GE}=3.986038 \times \mathrm{ro}^{11}$.

3. The factor $F_{2 .}$ - Let $a_{0}$ be the radius of an unperturbed circular orbit of the Moon with the same sidereal period as the actual sidereal month. Then

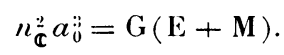

The solar attraction perturbs the Moon's orbit in such a manner that the actual mean distance of the Moon from the Earth is less than in unperturbed motion. The ratio is the scale of the variation orbit, found by E. W. Brown [4] to be

$$
\frac{a_{\mathbb{C}}}{a_{0}}=0.999093141975298
$$

Hence

$$
\mathrm{F}_{2}=\left(\frac{a_{\mathbb{\Phi}}}{a_{01}}\right)^{3}=0.9972818924
$$

Then

$$
\mathrm{G}(\mathrm{E}+\mathrm{M})=4.0350687 \times 10^{1:}
$$

and, with $\frac{\mathrm{E}}{\mathrm{M}}=8 \mathrm{r} .3 \mathrm{o}$,

$$
\mathrm{GE}=3.986040 \times 10^{14}
$$

4. The ratio $\frac{b}{a_{\mathbb{C}}} \cdot$ - The quotient of formulas (I) and (2) may be written

$$
\begin{aligned}
\frac{b^{2}}{a_{\mathbb{C}}^{2}} & =\frac{\mathbf{F}_{1}}{\mathbf{F}_{2}} n_{\mathbb{C}}^{2} \frac{a_{\mathbb{C}}}{g_{0}(\mathrm{I}+\mu)} \\
& =7.0909 \mathrm{I} 78 \times 10^{-12} \frac{a_{\mathbb{C}}}{g_{0}\left(\mathrm{I}+L^{\prime}\right)} .
\end{aligned}
$$


The expression for the sine of the Moon's mean horizontal parallax becomes

$$
\begin{aligned}
\frac{b}{a_{\mathbb{C}}} & =2.6628757 \times 10^{-i} a_{\mathbb{C}}^{\frac{1}{2}} g_{0}^{-\frac{1}{2}}(1+\mu)^{-\frac{1}{2}} \\
& =0.016592518 .
\end{aligned}
$$

With $\mu^{-1}=8 \mathrm{r} .3 \mathrm{o}, \quad g_{0}=9.7803, \quad a_{\mathbb{}}=3.844002 \times 10^{*}$, the equation yields

$$
b=6378 \mathrm{I} 67 \mathrm{~m} .
$$

The fact that this result agrees so well with the geodetic determination indicates that $\mu^{-1}=8 \mathrm{r} .3 \mathrm{o}$ is compatible with the values of $b, a_{\mathfrak{a}}, g_{0}$ adopted in this article. Further discussion is found in section 9 .

5. The ratio $\frac{b}{\Lambda} \cdot-$ Writing equation (I)

$$
g_{0} b^{3}=\mathrm{F}_{1} \mathrm{GE} b,
$$

and dividing by equation (3) yields after simple rearrangement

$$
\begin{aligned}
\frac{\mathrm{S}}{\mathrm{E}} \frac{b^{3}}{\mathrm{~A}^{\sharp 3}} & =\mathrm{F}_{1} \frac{k^{\prime 2} b}{g_{0}} \\
& =0.99^{8} 16500 \frac{k^{\prime 2} b}{g_{0}} .
\end{aligned}
$$

With the values for $k^{\prime 2}, b, g_{n}$ adopted it follows that

$$
\frac{\mathrm{S}}{\mathrm{E}} \frac{b^{3}}{\mathrm{~A}^{3}}=2.5803664 \times 10^{-8} .
$$

The solar parallax in seconds of arc is

$$
\bar{c}_{C}=206264^{\prime \prime} .81 \frac{1}{1} \text {; }
$$

thus

$$
\frac{\mathrm{S}}{\mathrm{E}} \pi_{\odot}^{3}=2.2644191 \times 10^{8}
$$

This agrees very nearly with the expression given by Spencer Jones [5] who used $2.26444 \times 10^{8}$.

The quantity obtained by the dynamical method of determining the solar parallax [6] is

$$
\frac{S}{E+M},
$$

which, if

$$
\mu=\frac{\mathbf{M}}{\mathbf{E}},
$$


requires the formula

$$
\frac{\mathrm{S}}{\mathrm{E}+\mathrm{M}} \pi:{ }_{\odot}=2.2644 \mathrm{I} 9 \mathrm{I} \times 1 \mathrm{IO}^{8}(\mathrm{I}+\mu)^{-1},
$$

so that the solar parallax obtained from this formula depends, but not very sensitively, on the value of $\mu$.

6. The ratio $\frac{\mathrm{A}}{a_{\mathbb{C}}} \cdot \mathrm{A}$ simple relation between $\mathrm{A}$ and $a_{\mathbb{C}}$ is obtained by taking the quotient of equations (2) and (3), or

or

$$
\begin{aligned}
& \frac{\mathrm{S}}{\mathrm{E}+\mathrm{M}}=\mathrm{F}_{2} \frac{k^{\prime 2}}{\mu_{\tilde{\mathbb{C}}}^{2}} \frac{\mathrm{A}^{\prime \prime}}{a_{\tilde{\mathbb{C}}}^{3}} \\
& =0.99728189 \frac{l^{\prime 2}}{n_{\mathbb{C}}^{2}} \frac{\Lambda}{a_{\mathbb{C}}^{*}} \\
& =0.0055800140 \frac{A^{3}}{a_{\mathbb{C}}^{3}}
\end{aligned}
$$

$$
\left(\frac{\mathrm{S}}{\mathrm{E}+\mathrm{M}}\right)^{\frac{1}{3}}=0.17-36929 \frac{\mathrm{A}}{a_{\mathbb{C}}} \text {. }
$$

The series of radar determinations of the Moon's mean distance at the Naval Research Laboratory (') gave

$$
\begin{gathered}
a_{\mathbb{C}}=3.844002 \times 10^{\times} \mathrm{m} . \\
\pm \mathrm{I} ?
\end{gathered}
$$

The advantage of the use of this formula is that it furnishes a relation between $\frac{S}{E+M}$ and $A$ without involving the ratio $\frac{M}{E}$. The table below shows the values of $\pi_{\odot}$ (for $\left.b=6.378 \mathrm{I} 66 \times 10^{9}\right)$ and $\frac{S}{\mathrm{E}+\mathrm{M}}$ as functions of $\mathrm{A}$.

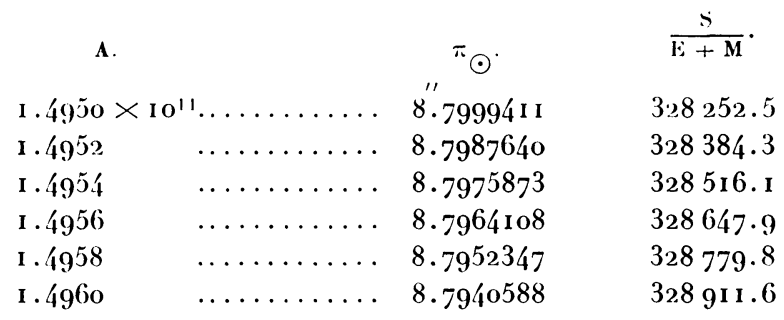

7. The Lunar inequality. - The lunar inequality is the coefficient of the periodic displacement of an object at a distance of one astronomical

(1) B. S. Yaplee, S. H. Knowles, H. Shapiro, K. J. Craig and D. Brouiver. The mean distance to the Moon as determined by radar, presented at this Symposium, See p. $8 \mathrm{r}$. 
unit in the plane of the Moon's orbit, caused by the motion of the Earth's center about the center of mass of the Earth-Moon system, the distance between the centers of Earth and Moon having its mean value $a_{\mathbb{C}}$.

The distance of the center of the Earth from the barycenter is $\frac{\mu a_{\mathbb{C}}}{I+\mu}$. Hence

$$
\mathrm{L}=206264^{\prime \prime} .8 \mathrm{I} \frac{\mu}{\mathrm{I}+\mu} \frac{a_{\mathbb{C}}}{\mathrm{A}} .
$$

The usual form is

$$
\mathrm{L}=\frac{\mu}{\mathrm{I}+\mu} \frac{\pi_{\odot}}{\sin \pi_{\overparen{C}}}
$$

which is equivalent, since

$$
\pi_{\odot}=206264^{\prime \prime} .81 \frac{b}{A}, \quad \sin \pi_{\mathbb{C}}=\frac{b}{a_{\mathbb{C}}} .
$$

Observational determinations are

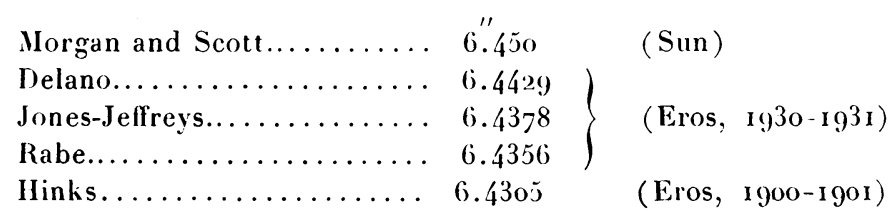

The determinations by Delano and by Jones-Jeffreys are probably the most reliable.

\begin{tabular}{|c|c|c|c|c|c|c|}
\hline \multirow{2}{*}{ A } & & \multicolumn{5}{|c|}{$u^{-1}$} \\
\hline & & 81.20 & 81.25. & 81.30 & 81.3 .5 & 81.40 \\
\hline $1.4950 \times 10^{11}$ & 1. & 6.4520 & $6.448 \mathrm{I}$ & 6.4442 & 6.4403 & 6.4364 \\
\hline I. 4952 & & 6.4511 & $6.447 \%$ & 6.4433 & 6.4394 & 6.1355 \\
\hline 1.4951 & & 6.4503 & 6.4464 & 6.4425 & 6.4385 & 6.4346 \\
\hline 1.4956 & $\ldots \ldots \ldots \ldots$ & $6.149 i$ & 6.4455 & 6.4416 & 6.4377 & 6.4338 \\
\hline I. 4958 & $\ldots \ldots \ldots \ldots$ & 6.4486 & 6.4447 & 6.4407 & 6.4368 & 6.4329 \\
\hline 1.4960 & $\ldots \ldots \ldots \ldots$ & 6.4477 & 6.4438 & 6.4399 & $6.436 \mathrm{o}$ & $6.4^{2} 21$ \\
\hline
\end{tabular}

With $a_{\mathbb{C}}=3.844002 \times 10^{*}$, values of $\mathrm{L}$ for adopted values of $\mu^{-1}$ are

Formulas (I) and (2) give the relation

$$
b^{2} g_{0}(\mathrm{I}+\mu)=\frac{\mathrm{F}_{1}}{\mathrm{~F}_{2}} n_{\mathbb{C}}^{2} a_{\mathbb{C}}^{3}=4.0276643 \times \mathrm{Io}^{14}
$$

- Thus, if $b$ and $g_{0}$ are obtained from geodetic determinations, a value of the ratio $\mu=\frac{M}{E}$ is obtained from the mean distance between the centers of the Earth and Moon. 
With

$$
\begin{aligned}
b & =6.378166 \times 10^{6} \\
g_{0} & =9.78030 \\
\mathrm{I}+\mu & =1.01230050 \\
\mu^{-1} & =81.29-5
\end{aligned}
$$

\begin{tabular}{|c|c|c|}
\hline \multicolumn{2}{|c|}{$1.4950 \times 10^{11} \ldots \ldots \ldots \ldots \ldots \ldots \ldots$} & 6.4444 \\
\hline I . 4952 & $\ldots \ldots$ & 6.4435 \\
\hline I. 4955 & . . & 6.4427 \\
\hline I. 4956 & $\ldots \ldots \ldots \ldots \ldots \ldots$ & 6.4418 \\
\hline I . 4958 & & 6.4409 \\
\hline I. 侮60 & $\ldots$ & 6.4401 \\
\hline
\end{tabular}

A. I.

The agreement between these computed values of $\mathrm{L}$ and the most reliable observed values is quite satisfactory. With percentage mean errors exhibited below,

$$
\begin{array}{rlrl}
a_{\mathbb{C}} & =3.84\left\{002 \times 10^{8}\right. & \left(\mathrm{I} \pm 0.30 \times 10^{--5}\right), \\
b & =6.378166 \times 10^{6} & \left(\mathrm{I} \pm 0.30 \times 10^{-5}\right), \\
g_{0} & =9.78030 & & \left(\mathrm{I} \pm 0.30 \times 10^{-5}\right)
\end{array}
$$

it follows that

$$
\begin{aligned}
\mathrm{I}+\mu & =\mathbf{1} .01230050\left(1 \pm \mathrm{I} .08 \times 10^{-5}\right) \\
\mu & =0.01230050\left(1 \pm 0.89 \times 10^{-3}\right) \\
\mu^{-1} & =8 \mathrm{I} .2975 \pm 0.072
\end{aligned}
$$

and, with

$$
\begin{aligned}
& \mathbf{\Lambda}=\mathrm{I} .496 \mathrm{o} \times \mathrm{I}^{11}, \\
& \mathrm{~L}=6.440 \mathrm{I} \pm 00057 \text { (m. e.) }
\end{aligned}
$$

The mean error is large compared with the mean error of direct determinations,

$$
\begin{array}{ll}
\mathrm{L}=6.4378 \pm 0.0018 & (\text { Jeffreys, I942) }[7] \\
\mathrm{L}=6.4429 \pm 0.0021 & (\text { Delano, I950) }[8]
\end{array}
$$

Thus the fact that the computed value of $\mathrm{L}$ based on the adopted values of $a_{\mathbb{C}}, b, g_{0}$ agrees so perfectly with the mean of the determinations by Jeffreys and by Delano is largely fortuitous; nevertheless the consistency of the data is pleasing. 


\section{REFERENCES.}

[1] I. Fischer, Astr. J., vol. 67,1962, p. 373.

[2] Y. KozaI, Smiths. Inst. Astrophys. Obs., Special Rep. 101, 1962.

[3] D. G. King-Hele, G. E. Cook and J. M. Rees, Nature, vol. 197, 1963, p. 785.

[4] E. W. Browx, Memoirs R. A.S., vol. 53, I897, p. 89.

[5] H. S. Jones, The Solar System II, ed. by Kuiper (G. P.), University of Chicago Press, p. I.

[6] E. RABe, Astron. J., vol. 55 , i950, p. i 12.

[7] H. JefFreys, Month. Not. R. A. S., vol. 102, 1942, p. 194.

[8] E. Delano, Astron. J., vol. 55, i950, p. I 29. 